\title{
Vicenç Furió
}

\section{JOAQUIM GARRIGA, IN MEMORIAM}

Joaquim Garriga i Riera va néixer a Malgrat el 1945. Després d'haver fet estudis a Roma, es va Ilicenciar en Història de I'Art el 1975 a la Universitat de Barcelona, i durant vint anys, del 1976 al 1996, va ser professor del nostre Departament, abans de ser-ho com a catedràtic a la Universitat de Girona. Aquestes línies no pretenen recordar amb detalls I'obra extraordinària que ens ha deixat. Per a qui vulgui conèixer la seva trajectòria $i$ publicacions, no hi ha res millor que llegir el text que ell mateix va redactar de la seva biografia acadèmica i intel-lectual per al Diccionari d'historiadors de l'art català de l'Institut d'Estudis Catalans, que es pot consultar en línia. D’altra banda, tampoc no gosaria valorar aquí els seus estudis i les seves decisives aportacions sobre temes de perspectiva o sobre l'art català de l'època moderna a Catalunya; entre altres coses, perquè no vaig ser alumne seu ni tampoc deixeble en sentit estricte. Malgrat tot, sempre I'he considerat el meu principal mestre, la persona de qui més he après sobre història de l'art i el nostre ofici. No em puc imaginar cap dels meus treballs acadèmics sense les seves opinions i els seus consells, sense el seu exemple d'exigència i rigor en el treball intel-lectual. Haver tingut la sort de gaudir de la seva amistat ha estat per a mi d'un valor inestimable.

Vaig conèixer Joaquim Garriga - Quim per als amics- quan jo acabava la llicenciatura d'Història de I'Art a la Universitat de Barcelona i ell ja era professor. Vam coincidir en el primer Consell $d^{\prime}$ Estudis que es va crear al Departament. Va ser en aquelles reunions, que aleshores fèiem a I'Institut Amatller, i a partir dels primers textos seus que vaig Ilegir - recordo la forta impressió que em va causar el volum Renacimiento en Europa, de la collecció «Fuentes y Documentos para la Historia del Arte», publicat per Gustavo Gili el 1983-que vaig adonar-me d'unes qualitats d'en Quim que des d'aleshores sempre vaig admirar: la finor dels seus criteris, I'amplitud dels seus coneixements, el rigor i l'exigència intel-lectual, la manera de descriure i argumentar, la seva prosa neta i rica, sempre orientada a explicar les coses amb la màxima precisió. 
En les reunions del Departament, en Quim aportava seny i les seves opinions eren sempre escoltades. Estic segur que parlo en nom de la majoria d'estudiants i professors d'aquells anys si dic com vam lamentar, malgrat entendre la seva decisió, que marxés a la Universitat de Girona, perquè entre nosaltres era un pal de paller, una persona estimada i respectada, un gran professor que ja feia de catedràtic, en el sentit de fer de mestre, abans de ser-ho a Girona.

Mai no va deixar de collaborar i d'interessar-se pels seus amics i collegues de la Universitat de Barcelona. Des que se'n va anar a treballar a Girona, quedàvem regularment per dinar en un restaurant xinès de la travessera de les Corts. Una de les preguntes que sempre em feia era com anaven les coses pel Departament. En aquests dinars, la conversa de sobretaula sempre s'allargava molt, i no recordo cap vegada, en més de vint anys, que no fóssim els últims de marxar del restaurant. Sobre temes d'art, en Quim era un conversador incansable. Estimava el seu ofici i estimava la universitat.

Amb ningú no he parlat tant d'història de I'art. Parlàvem d'artistes, d'obres, de viatges que havíem fet, de qüestions metodològiques, de llibres i lectures d'altres historiadors de l'art que admiràvem. En Quim va ser el primer professor que em va parlar de Gombrich, dels seus estudis sobre I'art del Renaixement i dels seus llibres sobre I'anàlisi de les imatges i els valors de la nostra cultura. Per a mi, en Quim va ser el meu Gombrich català, un model d'historiador de l'art que tenia la sort de tenir a prop, a qui consultava tots els meus dubtes i projectes professionals.

Escoltar en Quim quan descrivia una situació, com ara una conferència - la presentació d'un llibre d'algú que considerava una mica pedant o un venedor de fum, era presenciar una obra d'art. M'he referit al valor dels seus criteris, però no em puc oblidar de la finor i l'agudesa de les seves descripcions. Ni del tip de riure que ens havíem fet, no tant per explicar acudits, sinó per saber treure el suc a situacions ben quotidianes, com ara la dificultat de trobar un taxi sota la pluja, en l'últim viatge que vam compartir a París per veure exposicions.

Per a Joaquim Garriga no hi havia temes d'estudi petits. Molts vam aprendre d'ell que el rigor intel-lectual i la qualitat d'una recerca rauen en el mètode, no en si el tema és internacional o local. Qualsevol tema artístic, per petit que sigui, pot donar grans resultats si el mètode utilitzat és gran. Les seves classes i la seva recerca n'eren un model. Joaquim Garriga podia tractar amb un rigor i una riquesa de detalls sorprenents I'obra de gegants com Brunelleschi, Alberti o Leonardo, però també estudiava un tros d'escultura anònima amb una intensitat admirable si I'objectiu era millorar el coneixement i la catalogació del nostre patrimoni. Quan comen- 
çava a estudiar i a escriure sobre un tema, no el deixava fins que considerava que havia donat el millor d'ell mateix. I això era molt, moltíssim.

En Quim tenia totes aquestes qualitats. A més, les tenia sense mostrar cap mena de vanitat o presumptuositat. Era una persona entranyable, generosa i bondadosa. Les paraules amb les quals Ernst Gombrich va acabar un escrit de reconeixement i gratitud al seu amic Otto Kurz en el Ilibre Tributes. Interpreters of our cultural tradition, són plenament aplicables a Joaquim Garriga: no n'hi pot haver gaires com ell.

VicEnç Furió

Universitat de Barcelona

furio@ub.edu 